\title{
Sistem Rekrutmen dan Pelatihan terhadap Kompetensi Tenaga Pendamping Lokal Desa (PLD) di Kabupaten Karo
}

\author{
Jupianus Sitepu ${ }^{1)}$, Rafika Devi Saragih ${ }^{2)}$ \\ 1), 2) Universitas Quality \\ Email: jupianus.karona@gmail.com ${ }^{1)}$
}

\begin{abstract}
Village Local Assistance (PLD) is a program of the Ministry of Villages, Development of Disadvantaged Areas and Transmigration, the goal is Assistance to Village Government Wheels in terms of community social and village infrastructure. The purpose of this study is to analyze the effect of training recruitment on the competence of Village Local Assistants (PLD) in Karo district, also knows whether the perceived benefits moderate or mediate the effect of recruitment and training on the competence of Village Local Assistants (PLD) in Karo district. This research was conducted for one year. This research is a type of causality research, namely to examine the effect of recruitment and training on competence. This type of research data is primary data because it is carried out by means of field studies by distributing questionnaires. Data analysis was carried out using the SPSS veri 22 application. The results of this study were to determine the effect of recruitment and training on the competence of Village Local Assistants (PLD) throughout Karo district. Population 259 based on the equation in the Formulation Method and using a percentage of errors in sampling of 10\%, the number of samples obtained: 72 people. The population of this research is all village officials in Karo. The research sample in Karo district was taken as many as 72 people and to determine the magnitude of the influence of recruitment and training on PLD performance. Based on the hypothesis and research results, it can be seen that there is a positive effect of training on PLD performance but the effect of recruitment has not had a positive effect on PLD competence because has been tested using Partial $T$ and simple linear regression and the results are negative. And on the answer scores of all respondents, it can be seen from the category table.
\end{abstract}

Keywords: Regulation, Qualification, Value, Abillity

ABSTRAK

Pendamping Lokal Desa ( PLD) Adalah Program Kementerian Desa,Pembangunan Daerah Tertinggal dan Transmigrasi, tujuan nya adalah Pendampingan terhadap Roda Pemerintahan desa dalam hal sosial masyarakat dan Infrastruktur desa.. Tujuan penelitian ini menganalisa pengaruh rekrutmen pelatihan terhadap kompetensi Tenaga Pendampin Lokal Desa ( PLD ) se kabupaten Karo, juga mengetahui apakah manfaat yang dirasakan memoderasi atau memediasi permasalahan pengaruh rekrutmen dan pelatihan terhadap kompetensi Tenaga Pendampin Lokal Desa ( PLD ) se kabupaten Karo. Penelitian dilakukan selama satu tahun. Penelitian ini termasuk jenis penelitian kausalitas yaitu untuk menguji pengaruh antara Rekrutmen dan Pelatihan terhadap kompetensi. Jenis data penelitian ini yaitu data primer karena melakukan dengan cara studi lapangan dengan penyebaran kuesioner. Analisis data dilakukan dengan menggunakan aplikasi SPSS veri 22. Hasil penelitian ini yaitu untuk mengetahui pengaruh rekrutmen dan pelatihan terhadap kompetensi Tenaga Pendampin Lokal Desa ( PLD ) se kabupaten Karo. Populasi 259 berdasarkan persamaan pada Perumusan Metode dan menggunakan persentase kesalahan dalam pengambilan sampel sebesar 10\%, maka diperoleh jumlah sampel : 72 Orang. Populasi penelitian ini seluruh aparatur desa di Karo. Sampel penelitian Se kabupaten karo diambil sebanyak 72 orang dan untuk mengetahui besarnya pengaruh Rekrutmen dan pelatihan terhadap kinerja PLD.. Berdasarkan hipotesis dan hasil penelitian, dapat diketahui bahwa terdapat pengaruh yang positif dari Pelatihan terhadap kinerja PLD namun Pengaruh Rekrutmen belum berpengaruh Positif terhadap Kompetensi PLD karena sudah di uji dengan menggunakan Partial T dan Regresi linear sederhana dan hasilnya negatif. Dan Atas skor jawaban dari seluruh responden, dapat dilihat dari tabel kategori.

Kata Kunci: Peraturan,Kualifikasi,Nilai,Kemampuan

\section{Pendahuluan}

Sumber daya manusia (SDM) adalah salah satu faktor yang sangat penting, bahkan tidak dapat dilepaskan dari suatu organisasi. Sumber daya manusia memang bukan satu-satunya sumber daya yang dibutuhkan dan dimiliki oleh suatu organisasi, namun SDM merupakan sumber daya yang terpenting dalam menjalankan kegiatan perusahaan dan sangat mempengaruhi keberhasilan suatu perusahaan. Tanpa adanya sumber daya manusia, sumber daya lainnya tidak akan dapat bergerak sendiri. Sesuai dengan perkembangan jaman, tuntutan untuk SDM dalam penguasaan teknologi semakin tinggi. Oleh karena itu, SDM yang diperlukan saat ini adalah SDM yang sanggup 
menguasai teknologi dengan cepat, adatif, dan responsive terhadap perubahan-perubahan teknologi.

Pendamping Lokal Desa ( PLD ) Adalah Program Kementerian Desa,Pembangunan Daerah Tertinggal dan Transmigrasi, yang tujuan nya adlah Pendampingan terhadap Roda Pemerintahan desa dalam hal sosial masyarakat dan Infrastruktur desa.

Jumlah Pendamping Lokal Desa ( PLD ), merupakan salah satu dorongan untuk manajemen Tatakelola Desa agar dapat mengarahkan Perkembangan Pembangunan Dsa yang serba bisa atau dengan kata lain dapat diperbantukan ke bidang lain sewaktu-waktu apabila dibutuhkan yang berjumlah sebanyak 269 yang tersebar di Kabupaten Karo

Sesuai dengan keadaan jumlah PLD, manajemen Pemerintahan Desa membuat keputusan seluruh PLD yang ada dalam cakupan Desa harus memahami tugas dan tanggung jawab sebagian besar bagian-bagian yang ada di dalam Organik desa dan Perangkat desa, Kompetensi merupakan dimensi perilaku keahlian atau keungulan seorang pemimpin atau staf mempunyai keterampilan, pengetahuan yang baik. Dalam hal ini penulis ingin mengetengahkan dua faktor, yaitu faktor sistem rekrutmen, faktor pelatihan.

Penelitian ini memilih objek di seluruh desa se Kabupaten Karo, karena Kabupaten Karo, terkhusus di desa-desa Masih Minim Pembanguna secara sosial maupun secara Fisik dan Juga Ketepatan Penggunaaan Dana Desa ( ADD ), dan Pemahaman tentang Penggunaan ADD Juga Masih Minim dan sering tidak tepat sasaran Oleh perangkat desa, dan Bahwan adanya tumpang tindih kegiatan dengan instansi lain, sehingga anggaran menjadi Boros dan tidak tepat sasaran.

Selama tahun 2013 sampai dengan 2018 sangat terbatas Pelatihan, hal tersebut kemungkinan terjadi karena Selalu berpatokan ke juknis yang di lakukan oleh pemeintah pusat yang melakukan perekrutan setiap setiap tahunnya. Berdasarkan informasi yang didapat penulis bahwa, alasan seringnya terjadi perekrutan karena pergantian kTenaga PLD yang mengundurkan diri sebelum masa kontak berahir diakibatkan kurangnya kompetensi PLD dalam bidang yang diembannya.

\subsection{Kerangka Teori}

Variabel bebas dan variabel terikat dalam penelitian ini digambarkan dalam kerangka pemikiran teoritik sebagai berikut :

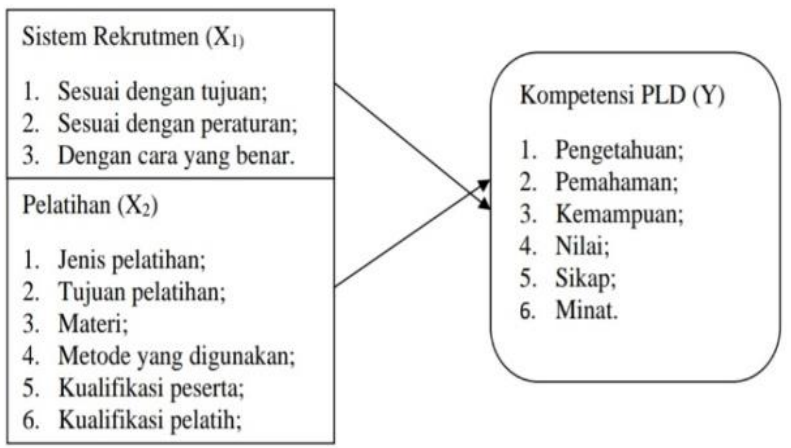

Gambar 1. Kerangka Teori

\subsection{Perumusan Masalah}

Perumusan masalah perlu dilakukan dalam kegiatan penelitian, perumusan masalah berfungsi untuk mempersempit permasalahan sehingga pelaksanaan penelitian dapat diarahkan pada satu permasalahan sehingga pemecahan masalah tidak mengambang dan diharapkan hasil penelitian akan optimal. Rumusan masalah dalam penelitian ini adalah : "Apakah sistem rekrutmen dan pelatihan berpengaruh terhadap kompetensi Tenaga Pendamping Lokal Desa?

\section{Landasan Teori}

\subsection{Manajemen Sumber Daya Manusia Berbasis Kompetensi}

Kondisi lingkungan bisnis di masa depan menunjukkan meningkatnya teknologi dan perubahan sosial. Di satu sisi harus mengikuti perkembangan teknologi, di sisi lain semakin meningkat tanggung jawab sosial organisasi. Sumber daya manusia perlu memahami kecendrungan organisasi multicultural dan keberagaman cultural. Keadaan tersebut menuntut sumber daya manusia untuk memiliki kompetensi dalam masingmasing bidangnya agar dapat menghadapi persaingan yang yang semakin intensif.

\subsection{Tujuan Rekrutmen}

Program rekrutmen yang baik perlu melayani banyak tujuan yang kadangkala bertentangan. Tujuan utama rekrutmen adalah menentukan atau mendapatkan pelamar yang berkualifikasi untuk dapat bergabung di dalam organisasi tersebut. Tujuan rekrutmen tersebut selalu mementingkan kelangsungan perusahaan, dapat berkembang dan bersaing melalui sumber daya manusia yang handal dan kompeten di dalamnya.

Menurut Kasmir (2016:95) pelaksanaan rekrutmen memiliki beberapa tujuan yang ingin dicapai, antara lain :

a. Memperoleh sumber tenaga kerja yang potensial;

b. Memperoleh sejumlah pelamar yang memenuhi kualifikasi;

c. Menentukan kriteria minimal untuk calon pelamar;

d. Untuk kebutuhan seleksi.

\subsection{Indikator Sistem Rekrutmen}

Kegiatan rekrutmen merupakan kelanjutan dari apa yang telah direncanakan dalam perencanaan tenaga kerja sebelumnya (Aldaman dkk., 2018). Kebutuhan tenaga kerja yang direncanakan baik dari segi jumlah maupun yang diinginkan harus segera direalisasikan sesuai waktu.

\subsection{Pengertian Pelatihan}

Pelatihan merupakan hal yang penting untuk semua karyawan khususnya karyawan baru, pelatihan sangat membantu mereka untuk cepat beradaptasi dengan pekerjaan yang dipercayakan kepada mereka, dan untuk karyawan lama pelatihan dapat meningkatkan kemampuan, keterampilan dan produktivitas mereka dalam bekerja (Heryati, 2018; Iswahyudar dkk., 2018; Putra, 2019; Roswaty \& Siddiq, 2019). 
Menurut Noe (2003) dalam Hasan dan Rusdiana (2015:161): "Pelatihan adalah usaha terencana untuk memfasilitasi karyawan dalam pembelajaran pengetahuan, keahlian, dan perilaku yang berhubungan dengan pekerjaan."

Menurut Kasmir (2016:126):"Pelatihan adalah proses untuk membentuk dan membekali karyawan dengan menambah keahlian, kemampuan, pengetahuan dan perilakunya."

\subsection{Faktor-Faktor yang Memengaruhi Pelatihan}

Pelatihan ditujukan untuk mengatasi kesenjangan antara pengetahuan, keterampilan, dan sikap yang dimiliki sesuai dengan tuntutan pekerjaan . tuntutan akan pelatihan yang efektif semakin hari semakin tinggi dan sangat diperlukan. Hal tersebut dikarenakan dinamika usaha yang terus bergerak dan senantiasa menuntut adanya upaya peningkatan kemampuan terutama dalam segi keterampilan. Tujuan perusahaan untuk dapat berkembang dan bertahan, dalam hal tersebut suatu perusahaan harus dapat bersaing di era global.

\subsection{Tujuan Penelitian}

Tujuan diadakannya penelitian ini adalah untuk menjawab dan menganalisa berbagai pernyataan yang tertera dalam rumusan masalah. Adapun tujuan penelitian ini adalah sebagai berikut :

1. Untuk mengetahui dan menganalisis pengaruh sistem rekrutmen terhadap kompetensi Tenaga Pendampng Lokal Desa

2. Untuk mengetahui dan menganalisis pengaruh pelatihan terhadap kompetensi Tenaga Pendamping Lokal Desa

3. Untuk mengetahui dan menganalisis pengaruh sistem rekrutmen dan pelatihan terhadap kompetensi Tenaga Pendamping Lokal Desa

\section{Metodologi}

Selama melakukan penelitian penulis akan berinteraksi dengan para PLD hingga bulan Desembr 2020 dan kemudian akan melakukan pengolahan hasil dari penelitian lapangan yang penulis lakukan sehingga menghasilkan jawaban penelitian yang penulis lakukan.

\section{Hasil dan Pembahasan}

\subsection{Populasi dan Sampel}

\subsubsection{Populasi}

Menurut Sugiyono (2005:74), “populasi adalah wilayah generalisasi yang terdiri atas objek atau subjek yang mempunyai kualitas dan karakteristik tertentu yang ditetapkan noleh peneliti untuk dipelajari dan kemudian ditarik kesimpulannya". Populasi yang akan dijadikan sumber dalam penelitian ini adalah Tenaga Pendamping Lokal Desa (TPL) di Kabupaten Karo. Dan populasi yang diambil adalah di seluruh kantor kepala desa seluruh di Kabupaten Karo. Jumlah seluruh desa di kabupaten karo sebanyak 259 desa dan setiap desa mempunyai 1 Tenaga Pendamping Lokal Desa (TPL) sehingga total populasi Tenaga Pendamping Lokal Desa (TPL) dikabupaten karo sebanyak 259 orang.

Tabel 1. Populasi jumlah Tenaga Pendamping Lokal Desa (TPL) di Kabupaten Karo

\begin{tabular}{|l|l|l|}
\hline No & $\begin{array}{l}\text { Struktur } \\
\text { Pemerintahan } \\
\text { Desa }\end{array}$ & $\begin{array}{l}\text { Jumlah Tenaga Pendamping } \\
\text { Lokal Desa (TPL) seluruh } \\
\text { kabupaten Karo }\end{array}$ \\
\hline 1 & $\begin{array}{l}\text { Tenaga Pendamping Lokal } \\
\text { Desa (TPL) }\end{array}$ & 259 \\
\hline & Jumlah & $\mathbf{2 5 9}$ \\
\hline
\end{tabular}

Tabel 2. Populasi kantor Kepala Desa se Kabupaten Karo

\begin{tabular}{|l|l|l|l|l|}
\hline No & $\begin{array}{l}\text { Struktur } \\
\text { Pemerintahan } \\
\text { Desa }\end{array}$ & $\begin{array}{l}\text { Jumlah Tenaga } \\
\text { Pendamping } \\
\text { Lokal Desa } \\
\text { (TPL) seluruh } \\
\text { kabupaten Karo }\end{array}$ & $\begin{array}{l}\text { Pengambilan } \\
\text { sampel }\end{array}$ & $\begin{array}{l}\text { Jumlah } \\
\text { Sampel }\end{array}$ \\
\hline 1 & $\begin{array}{l}\text { Tenaga } \\
\text { Pendamping } \\
\text { Lokal Desa } \\
\text { (TPL) }\end{array}$ & 259 & $\begin{array}{l}(259 / 259) \quad \text { x } \\
72\end{array}$ & 72 \\
\hline & Jumlah & 259 & & $\mathbf{7 2}$ \\
\hline
\end{tabular}

Tabel 3. Hasil Correlations Data kuesioner rekrutmen $\left(X_{1}\right)$

\begin{tabular}{|c|c|c|c|c|c|}
\hline & & X1.1 & $\mathrm{X} 1.2$ & $\mathrm{X} 1.3$ & $\mathrm{X} 1$ \\
\hline $\mathrm{X} 1.1$ & $\begin{array}{l}\text { Pearson } \\
\text { Correlation } \\
\text { Sig. (2-tailed) } \\
\mathrm{N}\end{array}$ & 40 & $\begin{array}{l}.463^{* *} \\
.003 \\
40\end{array}$ & $\begin{array}{l}.191 \\
.239 \\
40\end{array}$ & $\begin{array}{l}.626^{* *} \\
.000 \\
40\end{array}$ \\
\hline $\mathrm{X} 1.2$ & $\begin{array}{l}\text { Pearson } \\
\text { Correlation } \\
\text { Sig. (2-tailed) } \\
\mathrm{N}\end{array}$ & $\begin{array}{l}.463^{* *} \\
.003 \\
40\end{array}$ & $\begin{array}{l}1 \\
40\end{array}$ & $\begin{array}{l}.172 \\
.289 \\
40\end{array}$ & $\begin{array}{l}.692^{* *} \\
.000 \\
40\end{array}$ \\
\hline $\mathrm{X} 1.3$ & $\begin{array}{l}\text { Pearson } \\
\text { Correlation } \\
\text { Sig. (2-tailed) } \\
\mathrm{N}\end{array}$ & $\begin{array}{l}.191 \\
.239 \\
40\end{array}$ & $\begin{array}{l}.172 \\
.289 \\
40\end{array}$ & 40 & $\begin{array}{l}.782^{* *} \\
.000 \\
40\end{array}$ \\
\hline $\mathrm{X} 1$ & $\begin{array}{l}\text { Pearson } \\
\text { Correlation } \\
\text { Sig. (2-tailed) } \\
\mathrm{N}\end{array}$ & $\begin{array}{l}.626^{* *} \\
.000 \\
40\end{array}$ & $\begin{array}{l}.692^{* *} \\
.000 \\
40\end{array}$ & $\begin{array}{l}.782^{* *} \\
.000 \\
40\end{array}$ & 40 \\
\hline
\end{tabular}

**. Correlation is significant at the 0.01 level (2-tailed).

Tabel 4. Hasil Correlations Data kuesioner pelatihan $\left(X_{2}\right)$

\begin{tabular}{|c|c|c|c|c|c|c|c|c|c|}
\hline & & $\mathrm{X} 2.1$ & $\mathrm{X} 2.2$ & X2.3 & X2.4 & $\mathrm{X} 2.5$ & X2.6 & $\mathrm{X} 2.7$ & $\mathrm{X} 2$ \\
\hline $\mathrm{X} 2.1$ & $\begin{array}{l}\text { Pearson Correlation } \\
\text { Sig. (2-tailed) } \\
\mathrm{N}\end{array}$ & 40 & $\begin{array}{l}.233 \\
.147 \\
40\end{array}$ & $\begin{array}{l}-.013 \\
.939 \\
40\end{array}$ & $\begin{array}{l}.004 \\
.978 \\
40\end{array}$ & $\begin{array}{l}-.328^{*} \\
.039 \\
40\end{array}$ & $\begin{array}{l}-.046 \\
.777 \\
40\end{array}$ & $\begin{array}{l}.143 \\
.379 \\
40\end{array}$ & $\begin{array}{l}.234 \\
.147 \\
40\end{array}$ \\
\hline $\mathrm{X} 2.2$ & $\begin{array}{l}\text { Pearson Correlation } \\
\text { Sig. (2-tailed) } \\
\text { N }\end{array}$ & $\begin{array}{l}.233 \\
.147 \\
40\end{array}$ & $\begin{array}{l}1 \\
40\end{array}$ & $\begin{array}{l}.247 \\
.125 \\
40\end{array}$ & $\begin{array}{l}-.101 \\
.534 \\
40\end{array}$ & $\begin{array}{l}-.180 \\
.267 \\
40\end{array}$ & $\begin{array}{l}-.115 \\
.479 \\
40\end{array}$ & $\begin{array}{l}.059 \\
.719 \\
40\end{array}$ & $\begin{array}{l}.385^{*} \\
.014 \\
40\end{array}$ \\
\hline
\end{tabular}




\begin{tabular}{|ll|l|l|l|l|l|l|l|l|} 
X2.3 & Pearson Correlation & -.013 & .247 & 1 & -.047 & -.063 & $-.416^{* *}$ & .028 \\
& Sig. (2-tailed) & .939 & .125 & & .775 & .701 & .008 & .862 & .242 \\
& N & 40 & 40 & 40 & 40 & 40 & 40 & 40 & 40 \\
\hline X2.4 & Pearson Correlation & .004 & -.101 & -.047 & 1 & .109 & .132 & .174 \\
& Sig. (2-tailed) & .978 & .534 & .775 & & .503 & .417 & .284 & $.586^{* *}$ \\
& N & 40 & 40 & 40 & 40 & 40 & 40 & 40 & 40 \\
\hline X2.5 & Pearson Correlation & $-.328^{*}$ & -.180 & -.063 & .109 & 1 & -.117 & -.063 & .230 \\
& Sig. (2-tailed) & .039 & .267 & .701 & .503 & & .473 & .700 & .154 \\
& N & 40 & 40 & 40 & 40 & 40 & 40 & 40 & 40 \\
\hline X2.6 & Pearson Correlation & -.046 & -.115 & $-.416^{* *}$ & .132 & -.117 & 1 & $.409^{* *}$ & $.327^{*}$ \\
& Sig. (2-tailed) & .777 & .479 & .008 & .417 & .473 & & .009 & .039 \\
& N & 40 & 40 & 40 & 40 & 40 & 40 & 40 & 40 \\
\hline X2.7 & Pearson Correlation & .143 & .059 & .028 & .174 & -.063 & $.409^{* *}$ & 1 & $.613^{* *}$ \\
& Sig. (2-tailed) & .379 & .719 & .862 & .284 & .700 & .009 & & .000 \\
& N & 40 & 40 & 40 & 40 & 40 & 40 & 40 & 40 \\
\hline X2 & Pearson Correlation & .234 & $.385^{*}$ & .242 & $.586^{* *}$ & .230 & $.327^{*}$ & $.613^{* *}$ & 1 \\
& Sig. (2-tailed) & .147 & .014 & .132 & .000 & .154 & .039 & .000 & \\
& N & 40 & 40 & 40 & 40 & 40 & 40 & 40 & 40 \\
\hline
\end{tabular}

*. Correlation is significant at the 0.05 level (2-tailed).

Tabel 5. Hasil Correlations Data kuesioner Kompetensi (Y)

\begin{tabular}{|ll|l|l|l|l|l|l|l|}
\hline Correlations & Y1.1 & Y1.2 & Y1.3 & Y1.4 & Y1.5 & Y1.6 & X3 \\
\hline Y1.1 & Pearson Correlation & 1 & .144 & .007 & -.271 & -.075 & -.110 & .198 \\
& Sig. (2-tailed) & & .374 & .965 & .091 & .644 & .498 & .220 \\
& N & 40 & 40 & 40 & 40 & 40 & 40 & 40 \\
\hline Y1.2 & Pearson Correlation & .144 & 1 & .201 & -.023 & .202 & -.069 & $.549^{* *}$ \\
& Sig. (2-tailed) & .374 & & .214 & .887 & .210 & .672 & .000 \\
& N & 40 & 40 & 40 & 40 & 40 & 40 & 40 \\
\hline Y1.3 & Pearson Correlation & .007 & .201 & 1 & -.063 & -.012 & -.117 & $.461^{* *}$ \\
& Sig. (2-tailed) & .965 & .214 & & .699 & .943 & .474 & .003 \\
& N & 40 & 40 & 40 & 40 & 40 & 40 & 40 \\
\hline Y1.4 & Pearson Correlation & -.271 & -.023 & -.063 & 1 & -.178 & .171 & $.359^{*}$ \\
& Sig. (2-tailed) & .091 & .887 & .699 & & .271 & .292 & .023 \\
& N & 40 & 40 & 40 & 40 & 40 & 40 & 40 \\
\hline Y1.5 & Pearson Correlation & -.075 & .202 & -.012 & -.178 & 1 & -.070 & $.365^{*}$ \\
& Sig. (2-tailed) & .644 & .210 & .943 & .271 & & .668 & .021 \\
& N & 40 & 40 & 40 & 40 & 40 & 40 & 40 \\
\hline Y1.6 & Pearson Correlation & -.110 & -.069 & -.117 & .171 & -.070 & 1 & $.384^{*}$ \\
& Sig. (2-tailed) & .498 & .672 & .474 & .292 & .668 & & .014 \\
& N & 40 & 40 & 40 & 40 & 40 & 40 & 40 \\
\hline X3 & Pearson Correlation & .198 & $.549^{* *}$ & $.461^{* *}$ & $.359^{*}$ & $.365^{*}$ & $.384^{*}$ & 1 \\
& Sig. (2-tailed) & .220 & .000 & .003 & .023 & .021 & .014 & \\
& N & 40 & 40 & 40 & 40 & 40 & 40 & 40 \\
\hline
\end{tabular}

**. Correlation is significant at the 0.01 level (2-tailed).

*. Correlation is significant at the 0.05 level (2-tailed).

Tabel 6. Skor total $(X 1, X 2, Y)$

\begin{tabular}{|c|c|c|c|c|}
\hline Variabel & Indikator & R (hitung) & $\mathrm{r}$ (tabel) & Status \\
\hline \multirow[t]{3}{*}{ Rekrutmen (X1) } & $\mathrm{X} 1.1$ & 0.626 & 0.3120 & Valid \\
\hline & $\mathrm{X} 1.2$ & 0.692 & 0.3120 & Valid \\
\hline & $\mathrm{X} 1.3$ & 0.782 & 0.3120 & Valid \\
\hline \multirow[t]{7}{*}{ Pelatihan (X2) } & $\mathrm{X} 2.1$ & 0.234 & 0.3120 & \\
\hline & $\mathrm{X} 2.2$ & 0.385 & 0.3120 & Valid \\
\hline & $\mathrm{X} 2.3$ & 0.242 & 0.3120 & \\
\hline & $\mathrm{X} 2.4$ & 0.586 & 0.3120 & Valid \\
\hline & $\mathrm{X} 2.5$ & 0.230 & 0.3120 & \\
\hline & $\mathrm{X} 2.6$ & 0.327 & 0.3120 & Valid \\
\hline & $\mathrm{X} 2.7$ & 0.613 & 0.3120 & Valid \\
\hline \multirow[t]{6}{*}{ Kompetensi (Y) } & Y1.1 & 0.198 & 0.3120 & \\
\hline & Y1.2 & 0.549 & 0.3120 & Valid \\
\hline & Y1.3 & 0.461 & 0.3120 & Valid \\
\hline & Y1.4 & 0.359 & 0.3120 & Valid \\
\hline & Y1.5 & 0.365 & 0.3120 & Valid \\
\hline & Y1.6 & 0.384 & 0.3120 & Valid \\
\hline
\end{tabular}


$R$ Hitung menunjukkan korelasi antara skor pertanyaan dengan skor total $(\mathrm{X} 1, \mathrm{X} 2, \mathrm{Y})$ yang dapat digunakan untuk menguji validitas instrumen. Untuk mengetahui validitas pada setiap pertanyaan, maka nilai pada kolom total correlation yang merupakan nilai $r$ hitung dibandingkan dengan $r$ tabel. Adapun pada $\alpha=$ 0,05 dengan derajat bebas $\mathrm{df}=40$, sehingga $\mathrm{r}(0,05 ; 40)$, diperoleh $\mathrm{r}$ tabel adalah 0.3120 . Tabel 1.7 juga menunjukkan bahwa pertanyaan soal semua adalah valid, yang dapat dilihat dari $\mathrm{r}$ hitung pada total score correlation yang pada keseluruhan butir lebih besar dari $\mathrm{r}$ tabel $(0,3120)$.

\subsection{Hasil Uji Reliabilitas \\ 4.2.1 Uji Reliabilitas Data kuesioner rekrutmen $\left(X_{1}\right)$}

Tabel 7. Reliability $\left(X_{l}\right)$

\begin{tabular}{|l|l|} 
Reliability Statistics & N of Items \\
\hline Cronbach's Alpha & 3 \\
\hline .442 &
\end{tabular}

Item-Total Statistics
\begin{tabular}{|l|l|l|l|l|}
\hline & Scale Mean if \\
& $\begin{array}{l}\text { Scale } \\
\text { Variance if } \\
\text { Item Deleted }\end{array}$ & $\begin{array}{l}\text { Corrected } \\
\text { Item-Total } \\
\text { Correlation }\end{array}$ & $\begin{array}{l}\text { Cronbach's } \\
\text { Alpha if Item } \\
\text { Deleted }\end{array}$ \\
\hline X1.1 & 7.25 & 1.218 & .388 & .276 \\
X1.2 & 7.33 & .994 & .327 & .253 \\
X1.3 & 8.03 & .692 & .208 & .601 \\
\hline
\end{tabular}

Dari Tabel 7 dapat diketahui bahwa nilai ralpha sebesar 0,442 dan $r$ tabel. Sehingga dapat disimpulkan bahwa nilai $r$ alpha positif dan lebih besar dari $r$ tabel maka kuisioner tersebut dinyatakan reliabel dan dapat digunakan untuk penelitian.

\subsubsection{Uji Reliabilitas Data kuesioner pelatihan $\left(\mathrm{X}_{2}\right)$}

Tabel 8. Reliability $\left(X_{2}\right)$

Reliability Statistics

\begin{tabular}{|l|l|}
\hline Cronbach's Alpha & $\mathrm{N}$ of Items \\
\hline .006 & 7 \\
\hline
\end{tabular}

Item-Total Statistics

\begin{tabular}{|l|l|l|l|l|}
\hline & $\begin{array}{l}\text { Scale Mean if } \\
\text { Item Deleted }\end{array}$ & $\begin{array}{l}\text { Scale } \\
\text { Variance if } \\
\text { Item Deleted }\end{array}$ & $\begin{array}{l}\text { Corrected } \\
\text { Item-Total } \\
\text { Correlation }\end{array}$ & $\begin{array}{l}\text { Cronbach's } \\
\text { Alpha if Item } \\
\text { Deleted }\end{array}$ \\
\hline X2.1 & 22.7000 & 4.472 & -.018 & .018 \\
X2.2 & 22.8500 & 4.028 & -.005 & .012 \\
X2.3 & 23.7500 & 4.500 & -.105 & .095 \\
X2.4 & 23.0750 & 3.148 & .120 & $-.163^{\mathrm{a}}$ \\
X2.5 & 22.9750 & 4.640 & -.187 & .194 \\
X2.6 & 22.8500 & 4.233 & -.050 & .055 \\
X2.7 & 22.6000 & 3.323 & .335 & $-.310^{\mathrm{a}}$ \\
\hline
\end{tabular}

a. The value is negative due to a negative average covariance among items. This violates reliability model assumptions. You may want to check item codings.

\subsubsection{Uji Reliabilitas Data kuesioner Kompetensi (Y)}

Tabel 9. Reliability $(Y)$

Item-Total Statistics

\begin{tabular}{|l|l|l|l|l|}
\hline & $\begin{array}{l}\text { Scale Mean if } \\
\text { Item Deleted }\end{array}$ & $\begin{array}{l}\text { Scale } \\
\text { Variance if } \\
\text { Item Deleted }\end{array}$ & $\begin{array}{l}\text { Corrected } \\
\text { Item-Total } \\
\text { Correlation }\end{array}$ & $\begin{array}{l}\text { Cronbach's } \\
\text { Alpha if Item } \\
\text { Deleted }\end{array}$ \\
\hline Y1.1 & 19.5000 & 4.051 & -.165 & $-.019^{\mathrm{a}}$ \\
Y1.2 & 19.4750 & 3.025 & .228 & $-.460^{\mathrm{a}}$ \\
Y1.3 & 19.7250 & 3.230 & -.018 & $-.188^{\mathrm{a}}$ \\
Y1.4 & 19.7000 & 3.651 & -.147 & .007 \\
Y1.5 & 19.5750 & 3.584 & -.088 & $-.086^{\mathrm{a}}$ \\
Y1.6 & 19.6500 & 3.515 & -.071 & $-.108^{\mathrm{a}}$ \\
\hline
\end{tabular}

a. The value is negative due to a negative average covariance among items. This violates reliability model assumptions. You may want to check item codings.

\subsubsection{Deskriptif Responden}

Karakteristik responden pada penelitian ini dapat dilihat dari segi usia, jenis kelamin, dan masa kerja.

Tabel 10. Umur Kuesioner

\begin{tabular}{|l|l|l|}
\hline Umur & Jumlah Kuesioner & Persentase \\
\hline $24-35$ & 35 & 49 \\
\hline $36-47$ & 18 & 25 \\
\hline $48-59$ & 19 & 26 \\
\hline Jumlah & 72 & 100 \\
\hline
\end{tabular}

Secara keseluruhan, hasil jawaban dari butir-butir instrumen kuesioner dari variabel yang diteliti adalah sebagai berikut:

Tabel 11. Rekrutmen

\begin{tabular}{|l|l|l|l|l|l|l|l|l|l|l|}
\hline Pertanyaan & $\begin{array}{l}\text { Sangat } \\
\text { Tidak } \\
\text { Setuju (1) }\end{array}$ & $\%$ & $\begin{array}{l}\text { Tidak } \\
\text { setuju } \\
(2)\end{array}$ & $\%$ & $\begin{array}{l}\text { Kurang } \\
\text { Setuju } \\
(3)\end{array}$ & $\begin{array}{l}\text { Setuju } \\
(4)\end{array}$ & $\begin{array}{l}\text { Sangat } \\
\text { Setuju } \\
(5)\end{array}$ \\
\hline 1 & 0 & 0 & 0 & 0 & 2 & 3 & 34 & 48 & 36 \\
\hline 2 & 0 & 0 & 0 & 0 & 7 & 10 & 38 & 53 & 27 \\
\hline 3 & 0 & 0 & 5 & 7 & 24 & 34 & 28 & 41 \\
\hline
\end{tabular}

Hasil jawaban kuesioner yang diperoleh dari 72 orang responden untuk variabel Rekrutmen pada Tabel 11, yaitu:

a. Pada pertanyaan 1 (sesuai dengan tujuan) $3 \%$ menjawab Kurang Setuju, $48 \%$ menjawab Setuju dan $51 \%$ menjawab Sangat Setuju.

b. Pada pertanyaan 2 (sesuai dengan aturan) $10 \%$ menjawab Kurang Setuju, 53\% menjawab Setuju, dan $41 \%$ menjawab Sangat Setuju. c. Pada pertanyaan 3 (dengan cara benar) $7 \%$ menjawab Tidak Setuju, 34\% menjawab Kurang Setuju, 39\% menjawab Setuju, 39\% dan 21\% menjawab Sangat Setuju. 
Tabel 12. Hasil Pertanyaan

\begin{tabular}{|l|l|}
\hline Hasil pertanyaan & Keterangan \\
\hline $0 \%-19.99 \%$ & $\begin{array}{l}\text { Sangat (Tidak Setuju, Buruk atau Kurang } \\
\text { Sekali) }\end{array}$ \\
\hline $20 \%-39.99 \%$ & Tidak Setuju atau Kurang Baik \\
\hline $40 \%-59.99 \%$ & Cukup atau Netral \\
\hline $60 \%-79.99 \%$ & Setuju, Baik, atau Suka \\
\hline $80 \%-100 \%$ & Sangat (Setuju, Baik, Suka) \\
\hline
\end{tabular}

Tabel 13. Persentase Nilai Kuesioner

\begin{tabular}{|l|l|l|l|ll|}
\hline $\begin{array}{l}\text { Tidak } \\
\text { Setuju }\end{array}$ & $\begin{array}{l}\text { Kurang } \\
\text { Setuju }\end{array}$ & Setuju & $\begin{array}{l}\text { Sangat } \\
\text { Setuju }\end{array}$ & Total & \\
\hline 0 & $2 \times 3=6$ & $\begin{array}{l}34 \times 4= \\
136\end{array}$ & $\begin{array}{l}36 \times 5= \\
180\end{array}$ & $\begin{array}{l}322 / 360 \\
89.44\end{array}$ & $=$ \\
\hline 0 & $7 \times 3=21$ & $\begin{array}{l}38 \times 4= \\
152\end{array}$ & $\begin{array}{l}27 \\
135\end{array}$ & $\begin{array}{l}308 / 360 \\
85.55\end{array}$ & $=$ \\
& & $28 \times 4=$ & $15 \times 5=$ & $269 / 360$ \\
75 & & 74.72 & \\
\hline
\end{tabular}

Tabel 14. Pelatihan

\begin{tabular}{|c|c|c|c|c|c|c|c|c|c|c|}
\hline Pertanyaan & $\begin{array}{l}\text { Sangat Tidak Setuju } \\
\text { (1) }\end{array}$ & $\%$ & $\begin{array}{l}\text { Tidak } \\
\text { setuju (2) }\end{array}$ & $\%$ & $\begin{array}{l}\text { Kurang } \\
\text { Setuju (3) }\end{array}$ & $\%$ & $\begin{array}{l}\text { Setuju } \\
\text { (4) }\end{array}$ & $\%$ & $\begin{array}{l}\text { Sangat } \\
\text { Setuju (5) }\end{array}$ & $\%$ \\
\hline 1 & 0 & 0 & 0 & 0 & 15 & 21 & 37 & 51 & 20 & 28 \\
\hline 2 & 0 & 0 & 10 & 14 & 14 & 19 & 26 & 36 & 22 & 31 \\
\hline 3 & 0 & 0 & 12 & 17 & 13 & 18 & 24 & 33 & 23 & 32 \\
\hline 4 & 0 & 0 & 8 & 11 & 11 & 15 & 38 & 53 & 15 & 21 \\
\hline 5 & 0 & 0 & 6 & 8 & 9 & 13 & 28 & 39 & 29 & 40 \\
\hline 6 & 0 & 0 & 9 & 13 & 12 & 17 & 37 & 51 & 14 & 19 \\
\hline 7 & 0 & 0 & 7 & 10 & 9 & 13 & 21 & 29 & 35 & 49 \\
\hline
\end{tabular}

Hasil jawaban kuesioner yang diperoleh dari 72 orang responden untuk variabel Pelatihan pada Tabel 14 yaitu:

a. Pada pertanyaan 1 (Jenis pelatihan) $15 \%$ menjawab Kurang Setuju, 51\% menjawab Setuju, 28\% menjawab Sangat Setuju.

b. Pada pertanyaan 2 (Tujuan Penelitian) $14 \%$ menjawab Tidak Setuju, 19\% menjawab Kurang Setuju, 36\% menjawab Setuju dan 31\% menjawab Sangat Setuju.

c. Pada pertanyaan 3 (Materi) $17 \%$ menjawab Tidak Setuju, 18\% menjawab Kurang Setuju, $33 \%$ menjawab Setuju dan $32 \%$ menjawab Sangat Setuju.

d. Pada pertanyaan 4 (Motode yang digunakan) $11 \%$ menjawab Tidak Setuju, 15\% menjawab Kurang Setuju, 53\% menjawab Setuju dan 21\% menjawab Sangat Setuju.

e. Pada pertanyaan 5 (Kualifikasi Peserta) $8 \%$ menjawab Tidak Setuju, 13\% menjawab Kurang Setuju, 39\% menjawab Setuju dan 40\% menjawab Sangat Setuju. f. Pada pertanyaan 6 (Kualifikasi Pelatih) $13 \%$ menjawab Tidak Setuju, 17\% menjawab Kurang Setuju, 51\% menjawab Setuju dan 19\% menjawab Sangat Setuju.

g. Pada pertanyaan 7 (Waktu) $10 \%$ menjawab Tidak Setuju, $13 \%$ menjawab Kurang Setuju, $29 \%$ menjawab Setuju dan $49 \%$ menjawab Sangat Setuju.

Tabel 15. Kompetensi

\begin{tabular}{|c|c|c|c|c|}
\hline $\begin{array}{l}\text { Tidak } \\
\text { Setuju }\end{array}$ & $\begin{array}{l}\text { Kurang } \\
\text { Setuju }\end{array}$ & Setuju & $\begin{array}{l}\text { Sangat } \\
\text { Setuju }\end{array}$ & Total \\
\hline 0 & $15 \times 3=45$ & $\begin{array}{l}37 \times 4= \\
148\end{array}$ & $\begin{array}{l}20 \times 5= \\
100\end{array}$ & $\begin{array}{l}293 / 360= \\
81.38\end{array}$ \\
\hline $\begin{array}{l}10 \times 2= \\
20\end{array}$ & $14 \times 3=42$ & $\begin{array}{l}26 \times 4= \\
104\end{array}$ & $\begin{array}{l}22 \times 5= \\
110\end{array}$ & $\begin{array}{l}276 / 360= \\
76.66\end{array}$ \\
\hline $\begin{array}{l}12 \times 2= \\
24\end{array}$ & $13 \times 3=39$ & $\begin{array}{l}24 \times 4= \\
96\end{array}$ & $\begin{array}{l}23 \quad x \quad 5 \\
=115\end{array}$ & $\begin{array}{l}274 / 360= \\
76.11\end{array}$ \\
\hline $8 \times 2=16$ & $11 \times 3=33$ & $\begin{array}{l}38 \times 4= \\
152\end{array}$ & $\begin{array}{l}15 \times 5= \\
75\end{array}$ & $\begin{array}{l}276 / 360= \\
76.66\end{array}$ \\
\hline $6 \times 2=12$ & $9 \times 3=27$ & $\begin{array}{l}28 \times 4= \\
112\end{array}$ & $\begin{array}{l}29 \times 5= \\
145\end{array}$ & $\begin{array}{l}296 / 360= \\
82.22\end{array}$ \\
\hline $9 \times 2=18$ & $12 \times 3=36$ & $\begin{array}{l}37 \times 4= \\
148\end{array}$ & $\begin{array}{l}14 \times 5= \\
70\end{array}$ & $\begin{array}{l}272 / 360= \\
75.55\end{array}$ \\
\hline $7 \times 2=14$ & $9 \times 3=27$ & $\begin{array}{l}21 \times 4= \\
84\end{array}$ & $\begin{array}{l}35 \times 5= \\
175\end{array}$ & $\begin{array}{l}300 / 360= \\
83.33\end{array}$ \\
\hline
\end{tabular}

Tabel 16. Pertanyaan

\begin{tabular}{|c|c|c|c|c|c|c|c|c|c|c|}
\hline Pertanyaan & $\begin{array}{l}\text { Sangat } \\
\text { Tidak } \\
\text { Setuju } \\
\text { (1) }\end{array}$ & $\%$ & $\begin{array}{l}\text { Tidak } \\
\text { setuju (2) }\end{array}$ & $\%$ & $\begin{array}{l}\text { Kurang } \\
\text { Setuju (3) }\end{array}$ & $\%$ & $\begin{array}{l}\text { Setuju } \\
\text { (4) }\end{array}$ & $\%$ & $\begin{array}{l}\text { Sangat } \\
\text { Setuju } \\
\text { (5) }\end{array}$ & $\%$ \\
\hline 1 & 0 & 0 & 0 & 0 & 11 & 15 & 33 & 46 & 28 & 39 \\
\hline 2 & 0 & 0 & 0 & 0 & 14 & 19 & 41 & 57 & 17 & 24 \\
\hline 3 & 0 & 0 & 5 & 7 & 12 & 17 & 31 & 43 & 24 & 33 \\
\hline 4 & 0 & 0 & 6 & 8 & 9 & 13 & 37 & 51 & 20 & 28 \\
\hline 5 & 0 & 0 & 4 & 6 & 10 & 14 & 43 & 60 & 24 & 33 \\
\hline 6 & 0 & 0 & 5 & 7 & 12 & 17 & 29 & 40 & 26 & 36 \\
\hline
\end{tabular}

Hasil jawaban kuesioner yang diperoleh dari 72 orang responden untuk variabel Kompetensi pada Tabel 16, yaitu: a. Pada pertanyaan 1 (Pengetahuan) $19 \%$ menjawab Kurang Setuju, 57\% menjawab Setuju dan $39 \%$ menjawab Sangat Setuju. 
b. Pada pertanyaan 2 (Pemahaman) $19 \%$ menjawab Kurang Setuju, $57 \%$ menjawab Setuju, 24\% menjawab Sangat Setuju.

c. Pada pertanyaan 3 (Kemampuan) $7 \%$ menjawab Tidak Setuju, 17\% menjawab Kurang Setuju, 43\% menjawab Setuju dan $33 \%$ menjawab Sangat Setuju.

d. Pada pertanyaan 4 (Nilai) $8 \%$ menjawab Tidak Setuju, 13\% menjawab Kurang Setuju, 51\% menjawab Setuju dan 28\% menjawab Sangat Setuju.

e. Pada pertanyaan 5 (Sikap) 6\% menjawab Tidak Setuju, 14\% menjawab Kurang Setuju, 60\% menjawab Setuju dan 33\% menjawab Sangat Setuju.

f. Pada pertanyaan 6 (Minat) 7\% menjawab Tidak Setuju, 17\% menjawab Kurang Setuju, 40\% menjawab Setuju dan 36\% menjawab Sangat Setuju.

Tabel 17. Total Nilai Jawaban Kuesioner Kompetensi

\begin{tabular}{|l|l|l|l|l|}
\hline Tidak Setuju & Kurang Setuju & Setuju & Sangat Setuju & Total \\
\hline 0 & $11 \times 3=33$ & $33 \times 4=132$ & $28 \times 5=140$ & $305 / 360=84.72$ \\
\hline 0 & $14 \times 3=42$ & $41 \times 4=164$ & $17 \times 5=85$ & $291 / 360=80.83$ \\
\hline $5 \times 2=10$ & $12 \times 3=36$ & $31 \times 4=124$ & $24 \times 5=120$ & $290 / 360=80.55$ \\
\hline $6 \times 2=12$ & $9 \times 3=27$ & $37 \times 4=148$ & $20 \times 5=100$ & $287 / 360=79.72$ \\
\hline $4 \times 2=8$ & $10 \times 3=30$ & $43 \times 4=172$ & $24 \times 5=120$ & $330 / 360=91.66$ \\
\hline $5 \times 2=10$ & $12 \times 3=36$ & $29 \times 4=116$ & $26 \times 5=130$ & \\
\hline
\end{tabular}

\subsubsection{Hasil Analisis Regresi Linier Berganda}

Analisis regresi linear sederhana dilakukan dengan bantuan software SPSS versi 22 dengan tujuan untuk mengetahui seberapa besar pengaruh variabel bebas (X) terhadap variabel terikat $(\mathrm{Y})$ pada Kompetensi tenaga pendamping lokal desa (PLD) Di Kabupaten Karo.

Tabel 18. Cofficients

Coefficients $^{\mathrm{a}}$

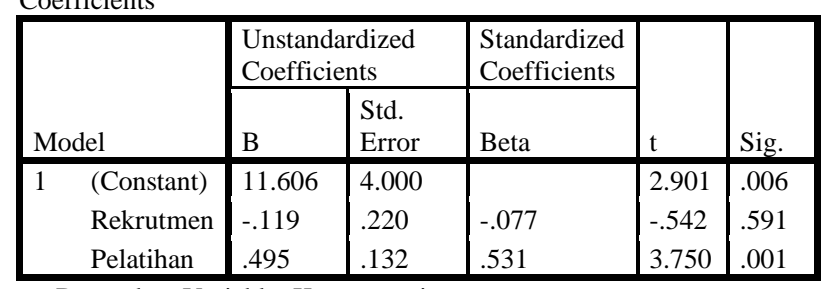

a. Dependent Variable: Kompetensi

Hasil estimasi dari persamaan regresi linier sederhana yang telah diperoleh, diambil dari kolom B yaitu Unstandarized coefficient, karena pada kolom tersebut terdapat nilai konstan, dimana dapat dibuat suatu interpretasi terhadap model atau hipotesis yang telah diambil pada metode penelitian yaitu : Konstanta bernilai 11.606 hal ini menunjukkan bahwa ada pengaruh (regresi) antara Rekrutmen, Pelatihan dengan Kompetensi, koefisien bertanda positif (+). Artinya ada pengaruh signifikan antara Rekrutmen, Pelatihan dengan Kompetensi sehingga jika Rekrutmen dan Pelatihan tinggi maka Kompetensi juga tinggi. Berdasarkan Tabel 1.9 juga dapat diperoleh persamaan regresi linier sederhana.

$\mathrm{Y}=11.606-0,119+0,495 \mathrm{X}$.

Dari persamaan tersebut, dapat digambarkan interpretasi model sebagai berikut: Konstanta (a) $=11.606$ menunjukkan harga konstan, dimana jika Variabel Rekrutmen $(\mathrm{X} 1)=0$ dan Pelatihan $(\mathrm{X} 2)=0$ maka Variabel Kompetensi (Y) pada Kompetensi bernilai 11.606 satuan Koefisien b (X1) $=-0,119$ dan $\mathrm{c}=(\mathrm{X} 2)=$ 0,495 menunjukkan bahwa Variabel antara Rekrutmen, Pelatihan berpengaruh positif terhadap Variabel Kompetensi (Y) pada Tenaga Pedamping Lokal Desa (PLD) Di kabupaten karo dan jika Variabel Pelatihan ditingkatkan sebesar satu satuan maka Pelatihan akan meningkat sebesar 0,495 .

Nilai signifikan $<0,05$, nilai $\mathrm{t}$ hitung $>\mathrm{t}$ tabel. $\mathrm{t}$ tabel $=\mathrm{t}(\mathrm{a} / 2 ; \mathrm{n}-\mathrm{k}-1)$, dimana $\mathrm{a}=5 \%=\mathrm{t}(0,05 / 2 ; 40-2-1$ )$=0,025 ; 37)=2.026$. sehingga nilai signifikasi $0,967>$ 0,05 . Nilai t hitung $0,042<2,026$. Hasil uji t parsial menunjukan bahwa nilai signifikansi mempunyai pengaruh Rekrutmen (X1) terhadap Kompetensi (Y) adalah $0,967>0,05$ dan nilai thitung $0,042<$ nilai tabel 2,026, maka H01 diterima dan Ha1 ditolak. Artinya tidak terdapat pengaruh Rekrutment (X1) terhadap Kompetensi (Y) secara signifikan.

\section{Kesimpulan dan Saran}

Rekomendasi yang diberikan penulis pada Pendamping local desa adalah agar terus meningkatkan Kompetensi PLD dan hal ini dapat diwujudkan melalui Pelatihan yang dapat meningkatkan kompetensi PLD dan setelah olah data juga hasilnya Pelatihan positf signifikan, hipotesis dan hasil penelitian, dapat diketahui bahwa terdapat pengaruh yang positif dari Pelatihan terhadap kinerja PLD namun Pengaruh Rekrutmen belum berpengaruh Positif terhadap Kompetensi PLD karena sudah di uji dengan menggunakan Partial $\mathrm{T}$ dan Regresi linear sederhana dan hasilnya negatif. Dan Atas skor jawaban dari seluruh responden, dapat dilihat dari tabel kategori. , dan saran penulis supaya terkait dengan Rekrutmen dalam PLD dapat di tingkatkan dalam metode atau pun sistem rekrutmennya supaya produk dari hasil rekrutment tersebut dapat di andalkan dan kompetensi PLD juga akan meningkat.

Adapun saran yang penelitian ini dapat sampaikan adalah sebagai berikut:

1. Pemerintah Diharapkan melakukan evaluasi dan pemantauan secara langsung menganai kinerja dari Pendamping Lokal Desa terkhusus tata cara rekrutmen PLD,

2. Pemerintah perlu merevisi kembali persyaratan rekrutmen Pendamping Desa mengenai kualifikasi pendidikan dan pengalaman kerja dari calon 
Pendamping Lokal Desa dan harus sesuai dengan bidang pekerjaan yang akan dilaksanakan.

3. Perlu adanya keterbukaan dan sosialisasi pada proses rekrutmen agar masyarakat bisa ikut mengawasi serta mengetahui apa saja standar penerimaan dari Pendamping Lokal Desa.

\section{Daftar Pustaka}

Abdullah, Ma'ruf, 2014. Manajemen dan Evaluasi Kinerja Karyawan, Aswaja Pressindo, Yogyakarta.

Aldaman, M., Marnisah, L., \& Kurniawan, M. (2018). Pengaruh Prestasi Kerja dan Promosi Jabatan Terhadap Kepuasan Kerja Karyawan Pada PT. Bank Mandiri TBK Kantor Cabang Bandar Lampung. Jurnal Ilmiah Ekonomi Global Masa Kini, 8(1), 37-42.

Basri, Hasan dan Rusdiana, 2015. Manajemen Pendidikan dan Pelatihan, CV Pustaka Setia, Bandung.

Kasmir, 2016. Manajemen Sumber Daya Manusia (Teori dan Praktek), PT. RajaGrafindo Persada, Jakarta.

Hasibuan, Malayu 2013. Manajemen Sumber Daya Manusia, PT. Bumi Aksara, Jakarta.

Heryati, A. (2018). Hubungan Antara Pendidikan dan Pelatihan (Diklat) K3 dan Pemberian kompensasi Terhadap Kinerja Karyawan PT. Kereta Api Indonesia (Persero) Devisi Regional III Palembang. Jurnal Ilmiah Ekonomi Global Masa Kini, 9(1), 71-76.

Iswahyudar, I., Halin, H., \& Roswaty, R. (2018). PENGARUH PELATIHAN TERHADAP KINERJA PEGAWAI PADA PERUM BULOG UNIT KECAMATAN MUARA TELANG KABUPATEN BANYUASIN PROVINSI SUMATERA SELATAN. Jurnal Ilmiah Ekonomi Global Masa Kini, 8(3), 69-73.

Mangkunegara, A. A. Anwar Prabu, 2013. Manajemen Sumber Daya Manusia Perusahaan, PT Remaja Rosdakarya, Bandung.

Putra, M. K. D. (2019). Pengaruh Pelatihan dan Pengembangan terhadap Kinerja Karywan Divisi Keamanan Aviation di Indonesia Angkasa Pura II (Persero) Palembang. Jurnal Ilmiah Ekonomi Global Masa Kini, 10(1), 25-31.

Roswaty, R., \& Siddiq, A. M. (2019). Analisis Pengaruh Pelatihan dan Pengembangan Sumber Daya Manusia Terhadap Kinerja Pegawai pada Dinas Pemberdayaan Perempuan dan Perlindungan Anak Kabupaten Musi Banyuasin Sumatera Selatan. Jurnal Ilmiah Ekonomi Global Masa Kini, 10(1), 63-69.

Samsudin, Sadili, 2010. Manajemen Sumber Daya Manusia, CV. Pustaka Setia, Bandung.

Siagian, Sondang P, 2013. Manajemen Sumber Daya Manusia, Bumi Aksara, Jakarta.

Sedarmayanti, 2015. Manajemen Sumber Daya manusia, PT. Refika Aditama, Bandung.
Sugiyono, 2010. Metode Penelitian Kuantitatif Kualitatif dan R\&D, Alfabeta, Jakarta.

Komar Richard, 2014, Hotel Manajemen, Grasindo, Jakarta.

Sujarweni Wiratna, 2015. SPSS Untuk Penelitian, Pustaka Baru Press, Yogyakarta.

Sumanto, 2014. Teori dan Aplikasi Metode Penelitian, PT. Buku Seru, Jakarta.

Sunyoto, Danang, 2012. Manajemen sumber Daya Manusia, Cetakan Pertama, PT. Buku Seru, Jakarta.

Sutrisno, Edy, 2015. Manajemen Sumber Daya Manusia, Cetakan ke-7, Kencana Prenadamedia Group, Jakarta.

Wibowo, 2014. Manajemen Kinerja. Edisi Keempat, PT. RajaGrafindo Persada, Jakarta.

Yani, H. M, 2012. Manajemen Sumber Daya Manusia, Mitra Wacana Media, Jakarta.

http://eprints.uny.ac.id/17098/1/TUGAS\%20AKHIR.pdf diakses 11 Oktober 2016, Pukul 21.32 wib.

http://repository.usu.ac.id/bitstream/123456789/44256/7/ Cover.pdf diakses 11 Oktober 2016, Pukul 19.02 wib.

http://repository.usu.ac.id/bitstream/123456789/53111/6/ Cover.pdf diakses 11 Oktober 2016, Pukul 18.01 wib. 